\title{
PENINGKATAN KUALITAS CUSTOMER SERVICE TELKOMSEL SURABAYA DENGAN METODE SERVICE QUALITY
}

\author{
${ }^{1}$ Benedictus Rahardjo, ${ }^{2}$ Septianda Angelica, ${ }^{3}$ Iviani Winoto, ${ }^{4}$ Natasah Bunardi, \\ ${ }^{5}$ Elma Cathlin Tangradi \\ 1,2,3,4,5 Fakultas Teknologi Industri, Jurusan Teknik Industri, Universitas Kristen Petra \\ e-mail: m25414060@john.petra.ac.id
}

\begin{abstract}
Service companies and products are well aware of the importance of customer-centered philosophy. This paper starts from the concept of service quality and is evidenced by the gap in it. This service quality concept is an appropriate approach used to determine the difference in value between customer expectations and perceptions. The dimensions used in this paper are tangible, reliability, responsiveness, assurance, and emphaty. This paper was conducted on mobile phone provider company by reviewing customer service in this company. Respondents involved in this research are 100 customer provider who have experience on this customer service. The results that will be obtained through this research is the gap of customer service and which aspects are important according to the customer so that company can improve its services and more developed.
\end{abstract}

Key words : Service quality; gap; customer; epectation; perceptions

\section{Abstrak}

Perusahaan jasa maupun produk sangat menyadari pentingnya filosofi customer-centered. Penelitian ini dilakukan dengan dimulai dari konsep mengenai service quality dan dibuktikan dengan gap yang ada di dalamnya. Konsep service quality ini merupakan pendekatan yang tepat digunakan untuk mengetahui perbedaan nilai antara ekspektasi dan harapan dari pelanggan. Dimensi yang digunakan dalam penelitian sevice quality ini adalah kondisi fisik (tangible), keandalan (reliability), daya tanggap (responsiveness), keamanan (assurance), dan kepedulian (emphaty). Penelitian ini dilakukan pada salah satu perusahaan provider telepon selular dengan meninjau dari pelayanan customer service di dalam perusahaan ini. Responden yang terlibat dalam penelitian ini adalah 100 pengguna provider yang memiliki pengalaman pada pelayanan customer service provider ini. Hasil yang akan didapatkan melalui penelitian ini adalah gap dari pelayanan customer service dan aspek mana yang penting menurut pelanggan sehingga perusahaan dapat memperbaiki pelayanannya dan lebih berkembang.

Kata kunci : Service quality; gap; pelanggan; harapan; kenyataan

\section{PENDAHULUAN}

Kepuasan pelanggan merupakan salah satu tantangan yang dimiliki oleh perusahaan terutama untuk perusahaan yang bergerak di bidang jasa. Perusahaan yang baik tidak hanya dinilai dari kualitas produk yang dihasilkan tapi juga berdasarkan kualitas pelayanan yang diberikan oleh perusahaan itu. Pelayanan yang baik dalam suatu perusahaan ini dapat mempertahankan pelanggan dan menyebabkan perusahaan dapat bertahan serta berkembang dalam jangka waktu yang panjang.

Penggunaan telepon selular telah sangat menjamur pada masyarakat akhir-akhir ini. Masyarakat tidak pernah lepas dengan penggunaan ponsel mereka untuk melakukan komunikasi maupun menggunakan internet. Aktivitas yang mereka lakukan menggunakan internet ini tentunya membutuhkan provider telepon selular yang baik. Telepon selular yang marak digunakan pada zaman ini adalah Global System for Mobile (GSM). Salah satu provider telepon selular berbasis GSM yang marak digunakan oleh masyarakat adalah Telkomsel.

Telkomsel merupakan salah satu provider telepon selular yang digemari oleh masyarakat akhir-akhir ini. Provider ini digemari masyarakat karena memiliki kualitas sinyal yang baik di daerah manapun, harga yang terjangkau, dan banyak promo lainnya. Penawaran-penawaran yang diberikan oleh Telkomsel ini sayangnya belum diketahui oleh semua pelanggan Telkomsel. Ketidaktahuan dan keterbatasan informasi yang dimiliki pelanggan membuat mereka enggan untuk menggunakan promo-promo yang ada di dalamnya dan akhirnya 
menyebabkan ketidakpuasan pelanggan. Keterbatasan informasi yang dimiliki oleh pelanggan ini mendorong perusahaan untuk membangun customer service di berbagai daerah agar dapat menjawab setiap kebutuhan dan kesulitan yang dirasakan oleh pelanggan Telkomsel.

Customer service Telkomsel telah tersebar di seluruh Indonesia. Salah satu kunci keberhasilan yang mendukung kepuasan pelanggan dalam perusahaan ini adalah dengan adanya layanan customer service. Tujuan dari penelitian ini adalah untuk mengetahui nilai yang diberikan pelanggan terhadap layanan customer service Telkomsel. Penelitian ini bertujuan untuk mengetahui pelayanan seperti apa yang dianggap penting dan memuaskan oleh pelanggan. Adapun batasan yang digunakan dalam penelitian ini adalah pengambilan data yang dilakukan pada pelanggan Telkomsel di daerah Surabaya saja

\section{METODE PENELITIAN}

Penelitian ini menggunakan metode kuantitatif dengan melakukan pengumpulan data menggunakan kuisioner. Data yang digunakan merupakan data primer dan data sekunder. Data primer didapatkan melalui hasil kuesioner dari responden. Data sekunder didapatkan dengan melakukan studi literatur melalui buku, jurnal, serta laporan yang berkaitan dengan penelitian ini. Langkah-langkah penelitian yang dilakukan adalah sebagai berikut:

1. Menentukan Jenis Penelitian

Jenis penelitian yang digunakan adalah penelitian deskriptif, yaitu memaparkan hasil pengolahan data untuk mengetahui penyebab utama terjadinya gap antara tingkat kepentingan dan tingkat kepuasan terhadap kinerja customer service Telkomsel

2. Menetukan Variabel Penelitian dan Skala Penelitian

Variabel yang digunakan dalam penelitian ini adalah kelima dimensi dari servqual yang dijabarkan dalam beberapa pertanyaan untuk tiap dimensi. Kelima dimensi tersebut yaitu Tangible (T1, T2), Reliability (R1, R2, R3 R4, R5), Responsiveness (Rs1, Rs2, Rs3, Rs4, Rs5), Empathy (E1, E2), dan Assurance (A1, A2, A3). Skala penelitian yang digunakan adalah skala likert dengan nilai 1-5. Penggunaan skala tersebut sama untuk pertanyaan tingkat kepentingan dan tingkat kepuasan. Semakin besar angka yang dipilih menunjukkan responden menyatakan suatu variable semakin penting atau semakin puas. Kolom N/A disediakan bagi responden yang tidak pernah merasakan/tidak mengetahui variabel layanan yang dinilai.

3. Menentukan Populasi Penelitian

Populasi dalam penelitian ini adalah 100 orang pengguna Telkomsel yang pernah mengunjungi dan mendapatkan pelayanan customer service Telkomsel

4. Melakukan Penyusunan Kuesioner

Penyusunan kuesioner dilakukan dengan memasukkan variabel dengan skala pengukuran likert, latar belakang responden (usia, jenis kelamin, pekerjaan). Kuisioner dapat dilihat pada Gambar 1.

5. Melakukan Pengumpulan Data

Pengumpulan data dilakukan dengan melakukan studi literatur mengenai topik yang diteliti, melakukan kunjungan lapangan untuk membagikan kuesioner di beberapa tempat customer service Telkomsel, dan melakukan observasi di kantor customer service Telkomsel. Uji Reliabilitas dan Validitas Data

Pengujian validitas menggunakan korelasi Pearson Product Moment. Nilai dinyatakan valid jika $\mathrm{r}$ hitung $>\mathrm{r}$ tabel, sedangkan nilai dinyatakan tidak valid jika $\mathrm{r}$ hitung $\leq \mathrm{r}$ tabel

Pengujian reabilitas dilakukan dengan membandingkan nilai pada kuisioner dengan nilai alpha. Kuisioner dinyatakan reliable jika memiliki nilai $>0.2277$

6. Melakukan Pengolahan Data

Pengolahan data dilakukan dengan menggunakan software SPSS Statistics dan Microsoft Excel.

7. Membuat Analisa dan Kesimpulan 
Analisa dibuat untuk mengetahui variable mana yang memiliki gap terbesar, lalu memberikan kesimpulan dan saran untuk petugas customer service Telkomsel agar dapat memperbaiki performa kinerjanya.

\section{HASIL DAN PEMBAHASAN}

Hasil dari pengumpulan data akan diuji validitas dan uji reliabilitas. Pengujian validitas digunakna untuk mengetahui semua pertanyaan layak dan dapat digunakan untuk analisa lebih lanjut. Pengujian reliabilitas digunakan untuk emngukur sejauh mana kuisioner dapat digunakan, dipercaya, dan diandalkan dalam penelitian. Uji validitas pada penelitian ini adalah perason's correlation product moment yang dianalisa menggunakan program SPSS. Tabel 1 adalah hasil uji validitas masing-masing pertanyaan dari segi presepsi konsumen.

Tabel 1. Hasil uji validitas persepsi konsumen

\begin{tabular}{lcccc}
\hline \multicolumn{1}{c}{ Dimensi } & Pertanyaan & Rhitung & Rtabel & Keterangan \\
\hline Tangible & 1 & 0,649 & 0,2277 & Valid \\
& 2 & 0,651 & 0,2277 & Valid \\
& 3 & 0,64 & 0,2277 & Valid \\
\hline Reliability & 4 & 0,691 & 0,2277 & Valid \\
& 5 & 0,65 & 0,2277 & Valid \\
& 6 & 0,691 & 0,2277 & Valid \\
& 7 & 0,691 & 0,2277 & Valid \\
\hline Responsiveness & 8 & 0,653 & 0,2277 & Valid \\
& 9 & 0,728 & 0,2277 & Valid \\
& 10 & 0,618 & 0,2277 & Valid \\
& 11 & 0,731 & 0,2277 & Valid \\
& 12 & 0,589 & 0,2277 & Valid \\
Empathy & 13 & 0,673 & 0,2277 & Valid \\
\hline Assurance & 14 & 0,687 & 0,2277 & Valid \\
& 15 & 0,722 & 0,2277 & Valid \\
\hline
\end{tabular}

Hasil dari uji validitas pada Tabel 1 menunjukkan bahwa semua butir pertanyaan dinyatakan valid. Hal itu dibuktikkan dengan nilai rhitung lebih besar daripada nilai rtabel pada taraf signifikan $10 \%$. Pengujian ini dapat disimpulkan bahwa seluruh butir pertanyaan dapat digunakan dan layak untuk dianalisa lebih lanjut. Tabel 2 adalah hasil uji validitas dari segi ekspetasi konsumen.

Tabel 2. Hasil uji validitas ekspektasi konsumen

\begin{tabular}{lcccc}
\hline \multicolumn{1}{c}{ Dimensi } & Pertanyaan & Rhitung & Rtabel & Keterangan \\
\hline Tangible & 1 & 0,58 & 0,2277 & Valid \\
& 2 & 0,607 & 0,2277 & Valid \\
& 3 & 0,669 & 0,2277 & Valid \\
\hline Reliability & 4 & 0,662 & 0,2277 & Valid \\
& 5 & 0,716 & 0,2277 & Valid \\
& 6 & 0,691 & 0,2277 & Valid \\
& 7 & 0,629 & 0,2277 & Valid \\
\hline Responsiveness & 8 & 0,633 & 0,2277 & Valid \\
& 9 & 0,675 & 0,2277 & Valid \\
& 10 & 0,601 & 0,2277 & Valid \\
& 11 & 0,65 & 0,2277 & Valid
\end{tabular}




\begin{tabular}{lcccc}
\hline \multicolumn{1}{c}{ Dimensi } & Pertanyaan & Rhitung & Rtabel & Keterangan \\
\hline & 12 & 0,717 & 0,2277 & Valid \\
& 13 & 0,707 & 0,2277 & Valid \\
\hline Empathy & 14 & 0,621 & 0,2277 & Valid \\
& 15 & 0,71 & 0,2277 & Valid \\
\hline Assurance & 16 & 0,698 & 0,2277 & Valid \\
& 17 & 0,655 & 0,2277 & Valid \\
& 18 & 0,681 & 0,2277 & Valid \\
\hline
\end{tabular}

Hasil uji validitas ekspetasi konsumen menunjukkan bahwa semua butir pertanyaan dinyatakan valid. Hal itu disebabkan nilai rhitung lebih besar dari rtabel dengan taraf signifikan $10 \%$. Hal ini berarti semua pertanyaan ekspetasi konsumen dapat digunakan dan dianalisa lebih lanjut.

Pengujian kedua adalah uji reliabilitas. Uji reliabilitas dilakukan ke presepsi konsumen dan ekspetasi konsumen. Pengujian reliabilitas menggunakan croanbach alpha. Koefisien penilaian reliabilitas adalah sebagai berikut:

- $0,8-1 \quad$ : Baik

- $0,6-0,799 \quad$ : Dapat diterima

- $<0,6 \quad$ : Kurang baik

Tabel 3 adalah hasil uji reliabilitas dari kuisioner.

Tabel 3. Hasil uji reliabilitas

\begin{tabular}{lr}
\hline Dimensi & \multicolumn{1}{c}{ Alpha } \\
\hline Persepsi & 0,93 \\
Ekspektasi & 0,934 \\
\hline
\end{tabular}

Hasil pengujian reliabilitas didapatkan bahwa nilai alpha dari masing-masing aspek berada di range 0,8-1 yang berarti bahwa setiap aspak bernilai baik dan aspek-aspek dari pertanyaan tersebut dapat dihandalkan/reliable.

Angket evaluasi kepuasan pelanggan disusun dalam penelitian ini dan diisi oleh seluruh pengguna Telkomsel. Pertanyaan angket evaluasi dapat dilihat pada Tabel 4. Aspek yang dimasukkan ke dalam angket evaluasi adalah kepuasan pelanggan terhadap 5 dimensi yaitu tangible, reliability, responsiveness, emphaty, dan assurance dalam perusahaan Telkomsel. Hasil dari kuisioner ini dibutuhkan untuk mengetahui gap atau selisih dari ekspektasi dan persepsi pelanggan terhadap pelayanan customer service Telkomsel. Perhitungan gap dilakukan untuk mengetahui selisih antara ekspetasi dan presepsi. Perhitungan gap dapat dirumuskan sebagai berikut:

dengan:

$$
\mathrm{SQ}=\mathrm{E}-\mathrm{P}
$$

$\mathrm{SQ}=$ Service Quality

$\mathrm{E}=$ Ekspetasi Konsumen

$\mathrm{P}=$ Presepsi Konsumen

Gap yang ditunjukkan pada perhitungan Tabel 4 menunjukkan perhitungan setiap dimensi agar dapat mengetahui seberapa jauh peran kelima dimensi tersebut dalam memberikan kualitas pelayanan. Rekapitulasi angket evaluasi yang telah diisi oleh 100 orang pelanggan dapat dilihat pada Tabel 4. 
Tabel 4. Hasil pengolahan data

\begin{tabular}{|c|c|c|c|c|c|}
\hline Kode & Aspek yang dinilai & Persepsi & Harapan & Gap & RK \\
\hline $\mathrm{T}$ & \multicolumn{5}{|c|}{ TANGIBLE } \\
\hline $\mathrm{T} 1$ & $\begin{array}{l}\text { Customer Service Telkomsel } \\
\text { memiliki tempat dan fasilitas yang } \\
\text { nyaman dan memadai }\end{array}$ & 0,2276 & 0,2356 & $-0,0079$ & \\
\hline $\mathrm{T} 2$ & $\begin{array}{l}\text { Customer Service Telkomsel } \\
\text { memiliki jumlah server yang } \\
\text { sesuai dengan antrian }\end{array}$ & 0,1888 & 0,2256 & $-0,0368$ & \\
\hline $\mathrm{T} 3$ & $\begin{array}{l}\text { Penggunaan nomor antrian di } \\
\text { Customer Service Telkomsel telah } \\
\text { berjalan sesuai dengan fungsinya }\end{array}$ & 0,1984 & 0,2289 & $-0,0305$ & \\
\hline & JUMLAH & 0,6148 & 0,6901 & $-0,0753$ & 3 \\
\hline $\mathrm{R}$ & \multicolumn{5}{|c|}{ RELIABILITY } \\
\hline $\mathrm{R} 1$ & 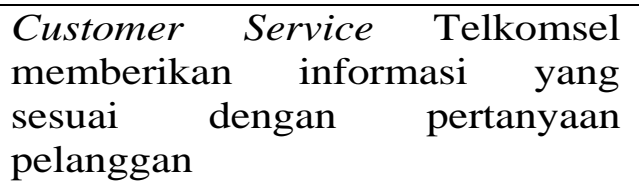 & 0,2241 & 0,2526 & $-0,0285$ & \\
\hline $\mathrm{R} 2$ & $\begin{array}{l}\text { Setiap karyawan Customer Service } \\
\text { Telkomsel menjawab pertanyaan } \\
\text { pelanggan secara konsisten }\end{array}$ & 0,2116 & 0,2278 & $-0,0162$ & \\
\hline R3 & $\begin{array}{l}\text { Pelayanan Customer Service } \\
\text { Telkomsel menjawab pertanyaan } \\
\text { pelanggan secara tepat, efektif, } \\
\text { dan menggunakan bahasa yang } \\
\text { baik, }\end{array}$ & 0,2207 & 0,2389 & $-0,0182$ & \\
\hline R4 & $\begin{array}{llr}\text { Customer Service } & \text { Telkomsel } \\
\text { berusaha menjawab } & \text { semua } \\
\text { pertanyaan pelanggan } & \end{array}$ & 0,2299 & 0,2367 & $-0,0067$ & \\
\hline R5 & $\begin{array}{l}\text { Karyawan Customer } \\
\text { Telkomsel memiliki data, } \\
\text { informasi, dan pengetahuan yang } \\
\text { baik dalam menjawab } \\
\text { pertanyaan pelanggan }\end{array}$ & 0,2207 & 0,2503 & $-0,0296$ & \\
\hline & JUMLAH & 1,1071 & 1,2063 & $-0,0992$ & 4 \\
\hline $\mathrm{RS}$ & \multicolumn{5}{|c|}{ RESPONSIVENESS } \\
\hline RS1 & $\begin{array}{l}\text { Customer Service Telkomsel } \\
\text { memberikan pelayanan yang } \\
\text { cepat kepada pelanggan }\end{array}$ & 0,1867 & 0,2378 & $-0,0511$ & \\
\hline RS2 & $\begin{array}{l}\text { Karyawan Customer Service } \\
\text { Telkomsel tidak pernah sibuk } \\
\text { untuk melayani pelanggan }\end{array}$ & 0,1867 & 0,2002 & $-0,0135$ & \\
\hline RS3 & $\begin{array}{l}\text { Karyawan Customer Service } \\
\text { Telkomsel } \\
\text { pelayanan dengan segera kepada } \\
\text { pelanggan }\end{array}$ & 0,1877 & 0,2267 & $-0,039$ & \\
\hline RS4 & $\begin{array}{l}\text { Pemberian estimasi waktu tunggu } \\
\text { dalam } \quad \text { Customer } \quad \text { Service } \\
\text { Telkomsel }\end{array}$ & 0,1733 & 0,2191 & $-0,0459$ & \\
\hline RS5 & $\begin{array}{l}\text { Waktu menunggu dalam Customer Service } \\
\text { Telkomsel sudah optimal }\end{array}$ & 0,1794 & 0,217 & $-0,0376$ & \\
\hline
\end{tabular}




\begin{tabular}{|c|c|c|c|c|c|}
\hline Kode & Aspek yang dinilai & Persepsi & Harapan & Gap & RK \\
\hline & JUMLAH & 0,9137 & 1,1008 & $-0,187$ & \\
\hline $\mathrm{E}$ & \multicolumn{5}{|c|}{ EMPATHY } \\
\hline E1 & $\begin{array}{l}\text { Karyawan Customer Service } \\
\text { Telkomsel melayani pelanggan } \\
\text { secara ramah dan sopan }\end{array}$ & 0,2116 & 0,2457 & $-0,0341$ & \\
\hline E2 & $\begin{array}{l}\text { Customer } \begin{array}{l}\text { Service Telkomsel } \\
\text { keinginan dan } \\
\text { memahami } \\
\text { kebutuhan pelanggan }\end{array} \\
\end{array}$ & 0,2139 & 0,2322 & $-0,0183$ & \\
\hline & JUMLAH & 0,4255 & 0,4779 & $-0,0524$ & 2 \\
\hline A & \multicolumn{5}{|c|}{ ASSURANCE } \\
\hline A1 & $\begin{array}{lcc}\text { Informasi } & \text { yang } & \text { diberikan } \\
\text { Customer } & \text { Service } & \text { Telkomsel } \\
\text { terjamin benar dan } & \text { akurat }\end{array}$ & 0,2288 & 0,24 & $-0,0113$ & \\
\hline A 2 & $\begin{array}{lcr}\text { Setiap } & \text { karyawan } & \text { Customer } \\
\text { Service } & \text { Telkomsel } & \text { menjaga } \\
\text { kerahasiaan pelanggan } & \end{array}$ & 0,2265 & 0,2457 & $-0,0193$ & \\
\hline A3 & $\begin{array}{l}\text { Pelanggan merasa aman dan } \\
\text { nyaman ketika dilayani oleh } \\
\text { karyawan Customer Service } \\
\text { Telkomsel }\end{array}$ & 0,243 & 0,2423 & 0,00066 & \\
\hline & JUMLAH & 0,6982 & 0,7281 & $-0,0299$ & 1 \\
\hline
\end{tabular}

Tabel 4 menunjukkan hasil rekapitulasi kuisioner kepuasan pelanggan pada customer service Telkomsel. Nilai seluruh dimensi yang ada menunjukkan nilai negatif yang berarti masih terdapat gap antara harapan yang diinginkan oleh pelanggan dan kenyataan yang terjadi di dalam pelayanan Telkomsel. Nilai gap ini tidak terlalu besar, tetapi masih bernilai negative yang berarti ekspetasi lebih besar daripada presepsi. Seluruh nilai negatif ini membuktikan bahwa seluruh dimensi yang terdapat dalam layanan customer service Telkomsel masih membutuhkan perbaikan. Dimensi yang memiliki ranking pertama adalah dimensi assurance dan dimensi yang paling terakhir adalah dimensi responsivene., Dimensi responsiveness yang memiliki nilai paling negatif ini menunjukkan bahwa dimensi ini perlu diprioritaskan untuk dilakukan perbaikan terlebih dahulu dalam perusahaan. Hasil dari nilai harapan dan kenyataan dapat dilihat pada diagram kartesius yang ditunjukkan pada Gambar 1.

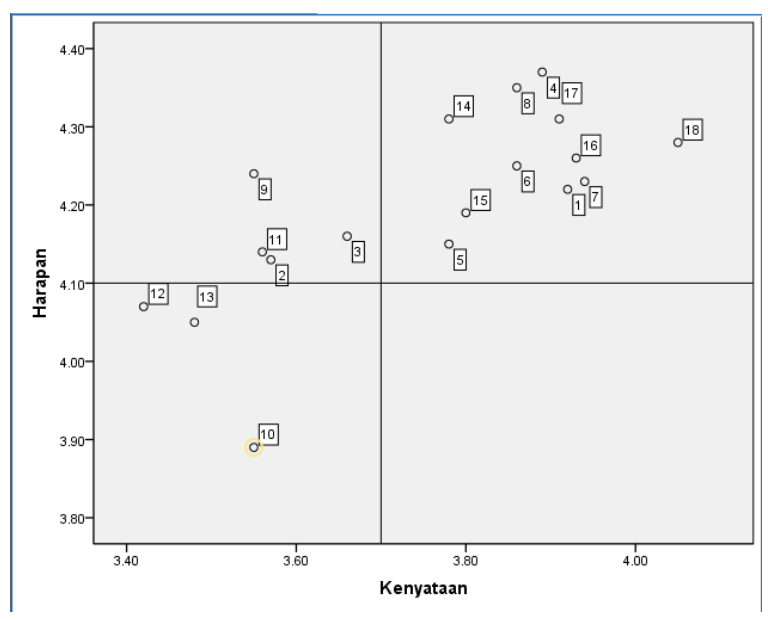

Gambar 1. Diagram kartesius 
Gambar 2 menunjukkan diagram kartesisus kenyataan dan harapan dari hasil angket evaluasi kepuasan pelanggan customer service Telkomsel. Masing-masing angka yang terdapat pada Gambar 2 mewakili kode pertanyaan pada kuisioner kepuasan pelanggan. Penjelasan angka-angka tersebut ditunjukkan sebagai berikut:

1. Angka 1: kode T1, customer service Telkomsel memiliki tempat dan fasilitas yang nyaman dan memadai.

2. Angka 2: kode T2, customer service Telkomsel memiliki jumlah server yang sesuai dengan antrian.

3. Angka 3: kode T3, penggunaan nomor antrian di customer service Telkomsel telah berjalan sesuai dengan fungsinya.

4. Angka 4: kode R1, customer service Telkomsel memberikan informasi yang sesuai dengan pertanyaan pelanggan.

5. Angka 5: kode R2, setiap karyawan customer service Telkomsel menjawab pertanyaan pelanggan secara konsisten.

6. Angka 6: kode R3, pelayanan customer service Telkomsel menjawab pertanyaan pelanggan secara tepat, efektif, dan menggunakan bahasa baik.

7. Angka 7: kode R4, customer service Telkomsel berusaha menjawab semua pertanyaan pelanggan.

8. Angka 8: kode R5, karyawan customer service Telkomsel memiliki data, informasi, dan pengetahuan yang baik dalam menjawab pertanyaan pelanggan.

9. Angka 9: kode RS1, customer service Telkomsel memberikan pelayanan yang cepat kepada pelanggan.

10. Angka 10: kode RS2, karyawan customer service Telkomsel tidak pernah sibuk untuk melayani pelanggan.

11. Angka 11: kode RS3, karyawan customer service Telkomsel memberikan pelayanan dengan segera kepada pelanggan.

12. Angka 12: kode RS4, pemberian estimasi waktu tunggu dalam customer service Telkomsel.

13. Angka 13: kode RS5, waktu menunggu dalam customer service Telkomsel sudah optimal.

14. Angka 14: kode E1, karyawan customer service Telkomsel melayani pelanggan secara ramah dan sopan.

15. Angka 15: kode E2, customer service Telkomsel memahami keinginan dan kebutuhan pelanggan.

16. Angka 16: kode A1, informasi yang diberikan customer service Telkomsel terjamin benar dan akurat.

17. Angka 17: kode A2, setiap karyawan customer service Telkomsel menjaga kerahasiaan pelanggan.

18. Angka 18: kode A3, pelanggan merasa aman dan nyaman ketika dilayani oleh karyawan customer service Telkomsel.

Diagram kartesius menunjukkan 4 bagian kuadran yaitu kuadran I, kuadran II, kuadran III, dan kuadran IV. Kuadran I menunjukkan pelanggan yang memiliki nilai harapan rendah dan nilai kenyataan rendah. Kuadran II menunjukkan pelanggan yang memiliki nilai kenyataan rendah dan nilai harapan tinggi. Kuadran III menunjukkan pelanggan yang memiliki nilai harapan dan kenyataan tinggi. Kuadran IV menunjukkan pelanggan yang memiliki nilai harapan rendah akan tetapi nilai kenyataan tinggi.

Gambar 2 membuktikan bahwa sebagian besar pelanggan berada di kuadran III. Hal yang perlu diperhatikan adalah angka 2, 3, 9, 11. Keempat angka ini menunjukkan harapan pelanggan yang tinggi namun kenyataan yang terjadi memiliki nilai yang rendah. Nilai 12 dan 13 meskipun berada di kuadran I, nilai yang dimiliki untuk harapan masih cukup tinggi dan kenyataan yang terjadi memiliki nilai yang rendah. Aspek yang menunjukkan nilai ini merupakan aspek yang perlu diperhatikan oleh perusahaan karena nilai yang diberikan oleh pelanggan tidak cukup baik sedangkan harapan yang dimiliki oleh pelanggan tinggi. Kualitas 
pelayanan customer service Telkomsel juga dapat dilihat pada nilai gap antara harapan dan kenyataan pelanggan.

Kualitas layanan customer service Telkomsel diwakili oleh nilai gap yang ditunjukkan pada Tabel 4. Hasil gap tertinggi dapat dilihat pada aspek customer service Telkomsel memberikan pelayanan yang cepat kepada pelanggan. Nilai negatif yang besar ini menunjukkan bahwa pelayanan customer service Telkomsel masih memiliki pelayanan yang lama sedangkan pelanggan memiliki harapan akan pelayanan yang cepat. Perubahan perlu dilakukan dalam aspek ini agar perusahaan dapat berkembang menjadi lebih baik. Hasil 5 gap tertinggi pada setiap aspek lainnya dapat dilihat pada Tabel 5.

Tabel 5. Hasil 5 gap tertinggi

\begin{tabular}{|c|c|c|}
\hline Kode & Aspek & Gap \\
\hline RS1 & $\begin{array}{l}\text { Customer Service Telkomsel memberikan pelayanan yang cepat } \\
\text { kepada pelanggan }\end{array}$ & $-0,0511$ \\
\hline RS4 & Pemberian estimasi waktu tunggu dalam Customer Service & $-0.045 \mathrm{c}$ \\
\hline RS3 & $\begin{array}{l}\text { Karyawan Customer Service Telkomsel memberikan pelayanan } \\
\text { dengan segera kepada pelanggan }\end{array}$ & $-0,0389$ \\
\hline RS5 & Waktu menunggu dalam Customer Service Telkomsel sudah optimal & $-0,0376$ \\
\hline E1 & $\begin{array}{l}\text { Karyawan Customer Service } \\
\text { secara ramah dan sopan }\end{array}$ & $-0,0341$ \\
\hline
\end{tabular}

Urutan 5 gap terbesar yang ditunjukkan pada Tabel 5, adalah aspek-aspek yang perlu diperhatikan oleh perusahaan karena kelima aspek ini memiliki nilai perbedaan yang cukup jauh antara ekspektasi dan persepsi pelanggan. Perbaikan untuk kelima aspek ini perlu dilakukan. Perbaikan yang tidak dilakukan segera dapat menyebabkan perusahaan kehilangan pelanggan dan tentunya merugikan perusahaan. Usulan perbaikan yang dapat diberikan pada perusahaan adalah sebagai berikut:

1. Customer service Telkomsel memberikan pelayanan yang cepat kepada pelanggan.

Aspek ini menunjukkan bahwa pelayanan yang diberikan kepada pelanggan terkesan berbelit-belit dan lama. Hal ini menyebabkan pelanggan menjadi menunggu hingga pelayanan selesai. Solusi yang dapat diterapkan adalah dengan setiap customer service harus dibekali informasi yang jelas dan tepat sehingga pada saat menjawab, customer service dapat menjawab dengan cepat dan tidak perlu berbelit-belit, Pemberian informasi dapat dilakukan dengan pelatihan dan tes yang diadakan oleh perusahaan untuk mengetahui pengetahuan setiap customer service. Pelatihan dan tes yang diadakan tidak perlu secara formal, tetapi dilakukan ketika customer service menganggur pada saat jam kerja,

2. Pemberian estimasi waktu tunggu dalam customer service Telkomsel.

Aspek ini menunjukkan nilai gap yang rendah karena beberapa customer service tidak memberikan estimasi waktu tunggu sehingga pelanggan tidak mengetahui waktu yang dibutuhkan untuk menunggu nomornya dipanggil. Sebaiknya perusahaan memberikan estimasi waktu tunggu di setiap customer service secara merata di setiap outlet.

3. Karyawan customer service Telkomsel memberikan pelayanan dengan segera kepada pelanggan.

Hal kurang memuaskan yang terjadi pada aspek ini adalah karyawan customer service yang seringkali meninggalkan pelanggan ketika sedang melakukan pelayanan. Sebaiknya diberikan SOP tambahan kepada seluruh karyawan untuk tidak meninggalkan pelanggan selama proses pelayanan dan melakukan pelayanan secepat mungkin.

4. Waktu menunggu dalam customer service Telkomsel sudah optimal,

Aspek ini berkaitan dengan bagaiman customer service melayani pelanggan. Apabila customer service melayani pelanggan lama dan berbelit- belit, maka pelanggan yang menunggu akan semakin lama. Customer service yang sering meninggalkan pelanggan ketika sedang melayani juga mempengaruhi waktu menunggu pelanggan selanjutnya. Solusi 
yang diterapkan adalah dengan memperbaiki kinerja customer service dalam melayani pelanggan sehingga dapat melayani dengan cepat dan tepat. Apabila customer service melayani dengan cepat dan tepat, maka waktu menunggu dapat diminimalkan.

5. Karyawan customer service Telkomsel melayani pelanggan secara ramah dan sopan Perlu adanya pelatihan terhadap seluruh karyawan customer service akan bagaimana menangani pelanggan dengan sikap yang ramah dan sopan. Pelatihan ini tentunya perlu dilakukan secara merata kepada seluruh karyawan Telkomsel agar karyawan di seluruh layanan customer service memiliki kemampuan pelayanan yang baik secara merata.

\section{SIMPULAN}

Berdasarkan hasil analisa gap antara kenyataan dan harapan, aspek responsiveness memiliki gap paling besar. Empat dari lima variabel yang memiliki nilai gap terbesar merupakan pertanyaan yang termasuk dalam aspek responsiveness. Pelanggan Telkomsel menginginkan pelayanan yang cepat, adanya estimasi waktu tunggu, memberikan pelayanan segera, dan waktu tunggu yang optimal. Perbaikan pada aspek responsiveness memiliki pengaruh yang berarti dalam meningkatkan kepuasan pelanggan, karena aspek tersebut memiliki nilai gap terbesar. Pelayanan customer service Telkomsel secara keseluruhan perlu ditingkatkan kembali, karena masih terdapat gap pada setiap dimensi pelayanan customer service Telkomsel. Hal ini menunjukkan bahwa customer service Telkomsel masih belum mampu memenuhi ekspektasi pelanggan secara keseluruhan. Hasil dari penelitian ini memiliki saran untuk customer service Telkomsel. Pertama adalah meningkatkan kecepatan pelayanan customer service, dengan memberikan SOP kepada karyawan untuk tidak meninggalkan counter tanpa alasan yang jelas. Kedua adalah memberikan training kepada karyawan mengenai cara melayani pelanggan secara efektif, cepat, tepat dan ramah. Hal ini sangat bermanfaat untuk mengoptimalkan waktu tunggu pelanggan dan meningkatkan kepuasan pelanggan dari segi keramahan karyawan.

\section{DAFTAR PUSTAKA}

Baloglu, S. (2002). Dimensions of Customer Loyalty. Cornell Hotel and Restaurant Administration Quarterly, 43(1), 47-59.

Kotler, P. (1997). Manajemen Pemasaran: Analisis, Perencanaan, Implementasi dan pengendalian (Edisi kedelapan). Arcella Ariwati Hermawan. Jakarta: Salemba Empat.

Kotler, P. (2002). Manajemen Pemasaran. Hendra Teguh dan Ronny A, Rusli. Jakarta: Prenhallindo.

Kuswandi. (2004). Cara Mengukur Kepuasan Karyawan. Jakarta: Bumi Aksara.

Lupiyoadi, T. (2008). Manajemen Pemasaran Jasa. Edisi 2. Jakarta: Salemba Empat.

Parasuraman, A., Zeithaml, V. A., Berry, L. L. (1985). A conceptual Model of Service Quality and its Implications for Future Research. The Journal of Marketing, 49(4), 41-50.

Peter, J. P., Olson, J. C. (1993). Consumer Behavior and Marketing Strategy. Homewood, IL: Irwin.

Setiyawati, A. (2009). Studi Kepuasan Pelanggan Untuk Mencapai Kepuasan Pelanggan (Studi Kasus Pada Konsumen Toko Bangunan Bangun Tejeki Semarang). Thesis. Semarang: Program Magister Manajemen Universitas Diponegoro.

Soelasih, Y. (2003). Analisis Kepuasan Konsumen terhadap Kualitas Pelayanan Hotel X di Jakarta. Telaah bisnis, 4(2).

Tjiptono, F. (2000). Manajemen Jasa. Yogyakarta: Andi Offset.

Tjiptono, F. (2006). Manajemen Jasa Edisi Keempat. Yogyakarta: Andi.

Usmara. (2003). Strategi Baru Manajemen Pemasaran. Yogyakarta: Amara Brooks. 
